\title{
Prevalence of hepatitis $B$ virus infection in vaccinated and non-vaccinated subjects in Bauchi, Nigeria
}

\author{
Kyauta Mallam Thomas, ${ }^{1}$ Patricia Manko Lar ${ }^{2}$, Hashimu Zakari ${ }^{3}$, Tabitha Vem Silas ${ }^{4}$ \\ ${ }^{1}$ Department of Microbiology, faculty of natural sciences University of Jos Nigeria \\ ${ }^{2}$ Department of Microbiology, Faculty of Natural Sciences, University of Jos, Nigeria \\ ${ }^{3}$ Department of Microbiology, Faculty of Natural Sciences, University of Jos, Nigeria \\ ${ }^{4}$ Department of Medical Laboratory Sciences, Faculty of health Sciences University of Jos Nigeria \\ DOI: 10.29322/IJSRP.11.12.2021.p12071 \\ http://dx.doi.org/10.29322/IJSRP.11.12.2021.p12071
}

\begin{abstract}
Objective: To investigate and compare the prevalent rate of hepatitis B virus infection in hepatitis B vaccinated and non-vaccinated in Bauchi Nigeria.

Methods: This Cross-sectional comparative research of HBV vaccinated and non-vaccinated was carried out between December 2020 and April 2021. Ethical clearance was obtained from the Bauchi State research ethics committee. Informed consent and questionnaire were used to obtain demographic data, $5 \mathrm{ml}$ of blood samples were collected and the study subjects were screened for HBsAg. Descriptive analysis using SPSS version 23 was used.

Results: Out of the 352 men and women study subjects enrolled in this study, it was revealed that of the one hundred and fifty-six non-vaccinated study subjects, 71(45.5\%) were positive for $\mathrm{HBcAb}$ as compared to $27(11.7 \%)$ in the vaccinated group. On the other hand, of the 156 non-vaccinated groups, 19(12.2\%) and $15\left(9^{\prime} 5 \%\right)$ were positive for $\mathrm{HBsAg}$ and $\mathrm{HBe}$ respectively. while 4(2\%) were positive for $\mathrm{HBsAg}$ out of which 2(1.0\%) were positive for $\mathrm{HBe}$ which is considered as breakthrough infection in the vaccinated group, both were statistically significant ( $P$ $=0.001$ ).

Conclusion: The prevalence of HBV among the nonvaccinated was obviously higher than in the vaccinated subjects. HBV vaccination at birth for infants and adults vaccination in areas with high endemic HBV might greatly reduce the transmission and the prevalence of hepatitis B infections.
\end{abstract}

\section{INTRODUCTION}

$\mathrm{H}$ epatitis B virus (HBV) has been known to be a blood-borne virus that affects the hepatic cells. Before the discovery of the virus by Samuel Blumberg in the 1960s, sexual intercourse and blood transfusion containing the viral agent was the primary route of its transmission, (Blumberg, 1977). But following the invention of a vaccine against $\mathrm{HBV}$ in the late 1980s, its rate of transmission and infection has been reduced drastically. Before various countries initiated the vaccination programs, children born to mothers who were already infected normally turned out infected at birth through contact with maternal blood seeded with the virus, (Turab, et al., 2018). This category of children has been reported to have the virus persisting in their blood for decades. Therefore, about $80-95 \%$ of these children are likely to develop chronic HBV infection. This can subsequently progress to chronic liver disease, thereby resulting in hepatocellular carcinoma (HCC), (Magaji, et al., 2021).

In Nigeria, in $2004 \mathrm{HBV}$ monovalent vaccine was introduced as one of the aspects of the National Program on Immunization (NPI), which is given at 6, 10, and 14 weeks of age. (NIP, 2002). Later in 2012, there was an introduction of pentavalent which consists of HBV, diphtheria, pertussis, tetanus, and Haemophilus influenza type B, (GAVI, 2015). This has been popularly known as HB and DPT is also known as a recombinant vaccine (Tritantrix- $\mathrm{HB}^{\mathrm{TM}}$ ) which is often followed by monovalent $\mathrm{HB}$ vaccine (Engerix-HB ${ }^{\mathrm{TM}}$ ). The vaccine's schedule administered at birth is 6,10 , and 14 weeks of life. In Nigeria, at present, the HB vaccine coverage is put between 25-75\% depending on the area or location, (Adebola, et al., 2016). The vaccine has proven helpful among the children vaccinated at birth by decreasing the rate of exposure and infection, (Olumuyiwa, et al., 2011,). However, the HBV vaccine has been found to either cause no response in some individuals. Estimates of 10-15\% vaccinated individuals have been reported to be non-responders to HBV vaccine, whereas $28 \%$ vaccinated children had been reported to produce no protective anti-HBs levels, (Fuad, et al., 2017). There is also a scenario called breakthrough infection that has been documented. This breakthrough infection refers to HBV infection among the vaccinated subjects who were vaccinated according to the standard laid down procedures, taking two or three doses following the right timing. The cause of which has not been ascertained, (Wiedermann, et al., 2016).

Globally, 350-400 million persons have been estimated to be carriers of HBV. While over 600 thousand persons worldwide are being diagnosed yearly with hepatocellular carcinoma which is said to be the second cause of cancer death, (Fuad, et al., 2017). In Nigeria, approximately a $12.2 \%$ prevalence rate was reported following the national survey, (Adebola, et al., 2016). Also, 8-15\% of unvaccinated adults have been reported to be carriers. This is predominantly evident among those involved in unprotected sex and patients with HIV-positive status, (Magaji, et al., 2021). However, lower rates have been reported in other parts of the country; in Enugu State, 4.3\% has been reported among children, (Uleanya \& Obidike, 2015). 5.7\% rate was reported from Ilorin, Kwara State in mothers and their preschool children, (Agbede, et al., 2007), and $4.3 \%$ have been reported from Port Harcourt, Rivers State in pregnant women, (Akani, et al., 2005), 
A handful of studies have been carried out on the prevalence of $\mathrm{HBV}$ infection among the general population in Nigeria, ranging from non-vaccinated, pregnant women, drugs addicts, and so many others. However, little or no attention has been given to the vaccinated subjects. The belief among people including healthcare workers is that, once one receives the HBV vaccine he is protected. Unfortunately, there are no institutions in Nigeria at both government and private levels vested with the responsibility of ascertaining vaccine immunogenicity in the vaccinated subjects. A study such as this tried to investigate and compare the rate of HBV infection among the vaccinated and non-vaccinated, including the level of their exposure to HBV in Bauchi Nigeria.

\section{MATERIALS AND METHODS}

This study was a cross-sectional investigation that was carried out in the eight wards of the Bauchi metropolis, Northeastern Nigeria: Hardo Ward, Dan'iya Ward, Makama Sarkin Baki 1 Ward, Makama Sarki 2 Ward, Majidadi A Ward, Majidadi B Ward, Dawaki Ward, and Dankade Ward respectively. The listed areas are the administrative units within the Bauchi metropolis. This study was carried out as comparative research between the HBV vaccinated and the non-vaccinated general population of the Bauchi metropolis that are from the ages of 1 year and above. The vaccinated subjects recruited included those who have received at least 2 doses or, and 3rd and the booster dose of the HepB vaccine following the appropriate schedule. The nonvaccinated subjects include those who have not received HepB vaccine not even one dose and are apparently healthy. Bauchi State is located in the Northeast of Nigeria where there has been secured for over a decade. This has led to the internal displacement of many who have ended up living for long in refugee camps or the movement of the people from the affected areas to the cities. Ethical clearance was sought and obtained from the Bauchi State Ministry of Health committee on research and ethics. Random sampling technique was employed in the recruitment of the study subjects having obtained their informed written consent. Interviewer-Questionnaire was used to collect demographic data that were relevant to this study, such as gender, age, marital status, number of vaccine doses, and date of the last dose. For children subjects, parents or caregivers were administered questionnaire to respond on their behalf. Five mills of venous blood were collected aseptically, spun, separated the serum, and used for the assays.

The plasma samples were used for the laboratory analysis to determine the HBV sero-makers. The HBV infection major seromarkers determined were: Hepatitis B core antibody (HBcAb), Hepatitis B surface antigen (HBsAg) and HBeAb. These markers were assayed using ProMed $®$ (Rapid diagnostic Kit Xinghu China) which is a rapid in-vitro monoclonalchromatographic qualitative test kit. It has a specificity and sensitivity of $98.8 \%$ and $100 \%$, respectively. The pouch of the kit was opened at the notch and the device was removed and placed on a clean flat surface. A hundred microlitres of plasma were applied on the device pad and allowed to stay for 15 minutes. The laboratory techniques were carried out following standard operating procedures as described by the manufacturer.

A sample result was positive (+) when a pink-colored band showed in the control realm $(\mathrm{C})$ in addition to a distinct pinkcolored band also in the test $(\mathrm{T})$ region. While a negative (-) result was when only one colored band appeared on the control (C) region, that is no apparent band on the test $(\mathrm{T})$ region whereas, if a color band was not visible in the control (C) region or a color band was only visible in the test region, the test was considered invalid. A procedural control was included in the test. A red line appearing in the control region $(\mathrm{C})$ is the internal procedural control. It confirms sufficient specimen volume and correct procedural technique. Any sample found positive for any of the markers was further subjected to Enzyme-Linked Immunosorbent Assay (ELISA) technique for confirmation using Ab ELISA Kit obtained from Abnova No. 108, Jhouzih St. Neihu District. Taipei City 114 Taiwan with a lot no: B21110PT, with 100\% sensitivity and specificity of $99.83 \%$. Laboratory analysis was carried out based on the manufacturer's instructions. Samples positive for $\mathrm{HBcAb}$ were considered to have been exposed to Hepatitis B virus in the past. While those positive for HBsAg were regarded to have $\mathrm{HBV}$ infection and those positive for $\mathrm{HBeAb}$ were considered to be at the stage of viral replication, and the HBV present was characterized using PCR. Therefore, those positive for $\mathrm{HBcAb}$ was used to calculate the rate of exposure to $\mathrm{HBV}, \mathrm{HBsAg}$ positives were used to determine the rate of $\mathrm{HBV}$ infection and $\mathrm{HBeAg}$ positive indicated possibility of progress to chronicity. Through identification number assigned to every study subject, individual's Laboratory findings were colligated to their corresponding data generated from their questionnaire.

\section{STATISTICAL ANALYSIS}

The data analysis was carried out using version 23 of the Statistical Package of Social Science (SPSS) (SPSS Inc., Chicago, IL, USA). Frequency and proportional rate were determined using qualitative data analysis. The correlations between the prevalence rate of seromarkers in the vaccinated and non-vaccinated were made using Chi-square tests on Epi Info version 6 and SPSS version-13 software. The $P \leq 0.05$ was considered significant.

\section{RESULTS}

In this study, three hundred and eighty-eight (388) study subjects were enrolled. However, thirty-six subjects $(9.3 \%)$ were excluded from the analysis, reasons being that: twenty-two (22) were as a result of an insufficient blood sample, 16 were from the vaccinated and 6 were in the non-vaccinated, 14 were as a result of protocol discrepancies (eleven were outside the age group inclusion criterion), 10 out of the 14 were part of the nonvaccinated and 4 from the vaccinated. While two in the vaccinated had problems due to technical error, the two bore the same Identification number.

Therefore, three hundred and fifty-two 352(90.7\%) study subjects were valid for the study analysis. Out of the 352 subjects, 196(50.5\%) were HepB vaccinated subjects while 156(40.2\%) were non-vaccinated subjects. However, the sample size was overestimated to include $10 \%$ attrition to complement subjects that might be excluded. The mean age (SD) of the vaccinated cohort was (32.5 years \pm 5.2$)$ with a range of $1-60$ years was significantly lower $(\mathrm{P}=0.027)$ compared to that of the non-vaccinated cohort (38.4 years \pm 9.6 ), whereas, the distribution of age group was comparable. Similarly, in both the two groups, the distribution of 
gender groups was comparable, $\mathrm{p}=0.018$. Males, $(\mathrm{n}=176)$ which is $50 \%$ of the total study subjects. In the vaccinated group, $136(69.4 \%)$ subjects had received at least 3 doses of the vaccine; while $60(30.6 \%)$ subjects had received but 2 doses and 16(8.2\%) had received the fourth dose of the vaccine. The number one objective of this study was to assess the study subjects' rates of exposure to HBV and seroprevalence in both $\mathrm{HB}$ vaccinated and non-vaccinated individuals, which are of course some of the most important HB markers.

The prevalence rates of these markers between both the study groups revealed that out of the one hundred and fifty-six non-vaccinated study subjects, 71(45.5\%) were found positive for $\mathrm{HBcAb}$ as compared to $27(11.7 \%)$ in the vaccinated group. There was a higher statistical significance as $\mathrm{P} \leq 0.001$ in the rate of exposure to HBV in the non-vaccinated subjects. Anti-HBc is a marker that defines whether or not a subject has been exposed to HBV. This, therefore, implies that the total number of subjects that were positive for anti-HBc is the rate of exposure to $\mathrm{HBV}$ in this study. On the other hand, of the 156 non-vaccinated groups, $19(12.2 \%)$ and $15(9.5 \%)$ were positive for $\mathrm{HBsAg}$ and $\mathrm{HBe}$ respectively as against $4(2 \%)$ and $2(0.5 \%)$ in the vaccinated group which was significantly higher $(\mathrm{P}<0.001)$ in the non-vaccinated group. HBsAg is a marker that reveals that a subject is infected or undergoing a process of infection. This by implication infers that the subjects that were positive for HBsAg are invariably the prevalence rate of $\mathrm{HBV}$ infection and those positive for $\mathrm{HBe}$ in the vaccinated are breakthrough infection rate in the study area.

Table 1: Socio-demographic features, and HBV vaccination status of subjects

\begin{tabular}{lccc}
\hline $\begin{array}{l}\text { Study group } \\
\text { Age (yrs) }\end{array}$ & $\begin{array}{c}\text { No. of vaccinated/ }(\%) \\
\mathbf{N = 1 9 6}\end{array}$ & $\begin{array}{c}\text { Non-vaccinated/ } \\
\mathbf{n = 1 5 6}\end{array}$ & P value \\
\hline Mean \pm SD & $32.5 \pm 5.2$ & $38.4 \pm 9.6$ & 0.027 \\
$1-10$ & $107(54.5)$ & $1(0.64)$ & \\
$11-20$ & $44(22.5)$ & $38(24.3)$ & \\
$21-30$ & $9(4.6)$ & $47(30.1)$ & \\
$31-40$ & $16(8.2)$ & $36(23.1)$ & \\
$41-50$ & $11(5.6)$ & $16(10.2)$ & \\
$>50$ & $9(4.6)$ & $18(11.5)$ & \\
Gender & & & \\
Male & $102(52)$ & $74(47)$ & \\
Female & $94(48)$ & $82(53)$ & \\
HB Vaccine dose & & & \\
2 doses & $60(30.6)$ & & \\
3doses & $120(61.2)$ & & \\
4doses & $16(8.2)$ & &
\end{tabular}

Table 1 shows the distribution of the study subjects in relation to their various socio-demographic characteristics and the number of vaccine doses received.

Table 2: Seromarkers of infection and exposure to $\mathrm{HBV}$ by vaccinated and non-vaccinated groups

\begin{tabular}{lccc}
\hline STUDY GROUPS & HBcAb $(\%)$ & $\begin{array}{c}\text { MARKERS } \\
\text { HBsAg }(\%)\end{array}$ & HBeAg \% \\
\hline Vaccinated $(\mathrm{n}=196)$ & $23(11.7)$ & $4(2.0)$ & $1(0.5)$ \\
Non-vaccinate $(\mathrm{n}=156)$ & $71(45.5)$ & $19(12.2)$ & $15(9.5)$ \\
P value & $\leq 0.001$ & $\leq 0.001$ & $\leq 0.002$ \\
& & & \\
\hline
\end{tabular}




\section{HEPATITIS B GENOTYPES IN CIRCULATION}

The samples that were found positive for HBe from both vaccinated and non-vaccinated were further considered for viral genotype characterization using multiplex PCR. The Genotyping principle was based on nested PCR system. Type specific primers: Primer sequence: hepBP1: 5, TCACCATATTCTTGGGAACAAGA-3 and hepBS1-2:5'CGAACCACTGAACAAATGGC-3' were employed for characterization of six genotypes A through $\mathrm{F}$ of $\mathrm{HBV}$ following a previous technique described by Naito et al. (2001). $20 \mu \mathrm{l}$ of Proteinase $\mathrm{K}$ was dispensed to a clean $1.5 \mathrm{ml}$ tube. Then $200 \mu \mathrm{l}$ of plasma was added. A volume of $200 \mu \mathrm{l}$ of Binding buffer (GC) was added to the sample and mix immediately by vortex mixer. The sample was completely re-suspended to achieve maximum lysis efficiency and it was incubated at $60^{\circ} \mathrm{C}$ for $10 \mathrm{~min}$. The extract was finally made and PCR set up: dH2O; 16ul. Predenaturation: $5 \mathrm{~min}$ at $95^{\circ} \mathrm{C}$, Denaturation: $40 \mathrm{sec}$ at $94^{\circ} \mathrm{C}$, Annealing: $40 \mathrm{sec}$ at $54^{\circ} \mathrm{C}$, Extension: $40 \mathrm{sec}$ at $72^{\circ} \mathrm{C} 35$ cycles, Final extension: $5 \mathrm{~min}$ at $72^{\circ} \mathrm{C}$. The result was run on $1.5 \%$ agarose gel electrophoresis. The PCR bands were then visualized by UV trans-illuminator box, (Biorad). The sizes of PCR products were estimated according to the migration pattern of a 100bp DNA ladder. The HBV genotypes were determined according to the amplified size of PCR product. Out of the $4(2 \%)$ of the vaccinated subjects that were positive for HBsAg, 2(1.0\%) turned out to be positive for HBe. The PCR result showed that both the two samples consisted of genotype $\mathrm{A}+\mathrm{B}$ each and 15 samples out of the 19 positives from the non-vaccinated were positive for HBe. 9(5.8\%) were genotype E, 4(2.6\%) were genotype E+B and $2(1.3 \%)$ were $\mathrm{A}+\mathrm{B}$ genotypes shown in table 3 below.

Table 3: Distribution of HBV genotype among the vaccinated and non-vaccinated study subjects

\begin{tabular}{lcc}
\hline HBV GENOTYPE & GROUPS \\
& HBV VSS $(\%)$ & HBV NVS $(\%)$ \\
\hline A+B & $2(1.0)$ & $2(1.3)$ \\
E & $0(0.0)$ & $9(5.8)$ \\
E+B & $0(0.0)$ & $4(2.6)$ \\
Negative & $195(100.0)$ & $140(89.7)$ \\
\hline Total & $196(100.0)$ & $156(100.0)$ \\
\hline
\end{tabular}

\section{DISCUSSION}

This study aimed at finding out the Seroprevalence rate of HBV infection in both the HBV vaccinated and non-vaccinated subjects through modern precise and specific elaborate gold standard technique. In the methodology, HBV Seroprevalence could be detected by a Rapid test kit that works by chromatographic principle. However, an enzyme-linked immune assay (ELISA) was used to confirm the results obtained by rapid kit. This study has revealed a prevalence rate of $\mathrm{HBsAg}$ of $19(12.2 \%)$ among non-vaccinated as against $4(2 \%)$ in the vaccinated group. Similarly, the rate of exposure (ant-HBc) to HBV was $71(46 \%$ in the non-vaccinated compared with $23(12 \%)$ in the vaccinated. There was a higher statistical significance in both the prevalence rates (HBsAg) and rate of exposure (anti$\mathrm{HBc}$ ) as $\mathrm{P} \leq 0.001$.

The significantly decreased HBV prevalence rate among the vaccinated compared with $12.2 \%$ in the national survey (Adebola, et al., 2016) is obviously a result of HepB immunization. However, the prevalence rate among the non-vaccinated is still within the WHO African Region estimate, (WHO, 2016). Similarly, Bauchi being a State in the Northeastern part of Nigeria revealed an HBV prevalence rate similar to some of the States in the same geopolitical zone. In Maiduguri, the State capital of Borno, a prevalence of $11.6 \%$ has been reported in blood donors and pregnant women, (Harry et al., 1994). However, it did not agree with $14.9 \%$ prevalence among healthy blood donors from Yola, the State capital of Adamawa State (Olokoba. et al., 2009). $17.1 \%$ from female sex workers in Nassarawa, (Forbi, et al., 2008) and $8.3 \%$ from Zaria among pregnant women, (Luka, et al., 2008). However, recently a study from Jos has reported $12.6 \%$ and $7.2 \%$ were reported from pregnant women with and without HIV respectively, (Magaji, et al., 2021). Insecurity in the Northeastern part of Nigeria might partly account for the HBV prevalence remaining within the WHO African region estimate. While vaccines rejection in Northern Nigeria following speculation that some vaccines cause barrenness may also be a contributing factor. This is obvious when compared with the prevalence rate from other States that are educationally advanced. 5.7\% rate was reported from Ilorin in mothers and their preschool children, (Agbede, et al., 2007) and 4.3\% has been reported from Port Harcourt in pregnant women, (Akani, et al., 2005),

HBV infection is a vaccine-preventable disease. The vaccine effectiveness against an-HBc was $84.7 \%$ with $95 \% \mathrm{CI}$ while effectiveness against infection was $84.8 \%$ (95\% CI). These findings agreed with the findings of a similar study carried out in the Niger State of Nigeria where Olumuyiwa, et al., (2011) reported a $43.2 \%$ prevalence rate of anti-HBc in non-vaccinated subjects and $10.5 \%$ in non-vaccinated subjects. They also reported an $11.8 \%$ prevalence rate of $\mathrm{HBsAg}$ in unvaccinated and $2 \%$ among the vaccinated cohorts. However, it does not agree with the report of Uneke, et al., (2005) where they reported a $14.3 \%$ prevalence rate of HBsAg among blood donors and $25.9 \%$ among HIV-positive patients in Jos Nigeria. Also, the prevalence rate of exposure to HBV does not concur with the report of sirisena, et al., (2002) and Eustance, et al., (2019) where they pointed in a study in Jos, Nigeria, and in a prevalence review of HBV in Nigeria respectively that about $75 \%$ of the Nigerian populace have been exposed to $\mathrm{HBV}$ at one time or the other. 


\section{CONCLUSION}

The non-vaccinated group had a higher prevalence of HBV infection compared with the vaccinated group in Bauchi. Similarly, the vaccinated group was found to have a significantly lower rate of exposure to HBV compared to the non-vaccinated group. However, it was amazing that appropriately vaccinated subjects were found to have $\mathrm{HBV}$ infection with genotypes $\mathrm{A}+\mathrm{B}$. This could be as a result of either receiving the vaccine when already infected or the infection set in while already vaccinated. To prevent infection in the vaccinated individuals, an institution ought to be set up that can predetermine individuals' HBV status before vaccination and post-ascertain the protection of the vaccinated. This can further decrease the prevalence both in vaccinated and non-vaccinated persons

Conflict of interest: None declared

\section{REFERENCES}

[1] Abba, O.J., Anejo, J.A., Akindgh, T.M., Smbo, N., Pwol, R., Fadairo-Isah, Y., Agbaji, O.O., Oguche, S., Idoko, J.A. (2014). Immune response to recombinant purified Hepatitis B surface antigen vaccine among health care workers in Jos North Central, Nigeria. IOSR Journal of Dental and Medical Sciences. Vol 13, issue 7 ver iii pp 6164.

[2] Adebola, T., O., Akin, O., Muhammad, S., Balogun, A., A., Patrick, N., Moses, A.,Abiodun, E. O., Simeon, W. A., $\quad$ Samuel, S., Bolanle, O. P., Musa, S. and Abdulsalami, N. (2016). Seroprevalence of Hepatitis B Infection in Nigeria: A National Survey. American Journal of Tropical Medical Hygiene, 95(4): 902-907.

[3] Agbede, OO., Iseniyi, JO., Kolewale, MO., \& Ojuawo, A. (2007). Risk factors and seroprevalence of hepatitis B antigenemia in mothers and their preschool children in Ilorin, Nigeria. Therapy 4: 6772.

[4] Ahizechukwu, CE., Uoamaka, AE., Charles, IO., Ifeanyichukwu, UE., Chukwuanugo, O. Prevalence, correlates and pattern of hepatitis B surface antigen in a low resource stting. $\quad$ Virol J 2011; $8: 12$

[5] Akani, CI., Ojule, AC., Opurum, HC., Ejilemele, AA. (2005). Seroprevalence of HBsAg in pregnant women in Port Harcourt. Niger Postgrad Med J 12: 266-270.

[6] Baldovin, T., Mel, R., Bertoncello, C., Carpene, G., Soppelsa, F., Gilberti, A., and Baldo, V., (2012). Persistence of Immunity to Tickborne Encephalitis after Vaccination and Natural Infection. J Med Virol 84(8): 1274-8.

[7] Black, AP, Nouanthong, P, Nanthavong, N., Souvannaso, C., Vilivong, K., Jutavijittum, P., Samountry, B., Lütteke, N., Hübschen, JM., Goossens, S., Quet, F., Buisson Y, Muller CP. (2014). Hepatitis B virus in the Lao People's Democratic Republic: a cross sectional serosurvey in different cohorts. BMC Infect Dis 14: 457-460.

[8] Blumberg, BS. (1977). Australia antigen and the biology of hepatitis B. Science; 197: 17-25.

[9] Forbi, JC., Onyemauwa, N., Gyar, SD., Oyeleye, AO., Entonu, P., Agwale, SM. (2008). High prevalence of hepatitis B virus among female sex workers in Nigeria. Rev Inst Med Trop Sao Paulo 50: 219-221.

[10] Fuad, AAA., Naila, AA., Fawzi, A., Nader., SA., Mohammed SA., Tari, G., $\mathrm{BH}$ and Atif AE, (2017). Assesment of Immunization to Hepatitis Vaccine among Children under Five Years in Rural Areas of Taiz, Yemen. Hepatitis Resaerch and Treatment. 21: 31-37.

[11] GAVI, (2015). Nigeria Launches Pentavalent Vaccine. Available at: http://www.gavi.org/Library/News/GAVI

features/2012/Nigerialaunches-pentavalent vaccine/. Accessed June 24,2015

[12] Harry, TO., Bajani, MD., Moses, AE. (1994). Hepatitis B virus infection among blood donors and pregnant women in Maiduguri, Nigeria. East Afr Med J 70: 596-597.
[13] Hou, J., Liu, Z., \& Gu F. (2005). Epidemiology and prevention of hepatitis B virus infection. Int J Med Sci 2: $50 \quad 57$.

[14] Keane, E., Funk, AI., Shimakawa, Y. (2016). Systematic review with metaanalysis: the risk of mother-to child transmission of hepatitis B virus infection in sub-Saharan Africa. Aliment pharmaco Ther; 44:105-17.

[15] Kubba, AK., Taylor, P., Graneek, B., Strobel, S. (2003). Non-Responders to Hepatitis B vaccination: A Review. Commun Dis Public Health; 6(2): 106-12.

[16] Luka, SA., Ibrahim, MB., Iliya, SN. (2008). Seroprevalence of hepatitis B surface antigen among pregnant women attending Ahmadu Bello University Teaching Hospital Zaria. Niger J Parasitol 29: 38-41.

[17] Magaji, F.A., Okolo, M.O., Yiltok, E.S., Golt, W., Anzaku, S.A., Ogwuche, J.,Pam, V.C., Ocheke, A.N., Musa, J., Isichie, C., Imade, G.E., Mutihir, J.T., Ugwu, B.T., Agbaji, O., Sagay, S.A., Zoakanh, A.I., aa \&Chn, S.E. (2021). Prevalence of Hepatitis B virus Infection in Pregnant Women with and Without HIV in Jos, Nigeria. International Journal of Infectious Diseases. 104:276-281

[18] Mei-Hwei, Chang. (2010). Breakthrough HBV infection in vaccinated children in Taiwan, Surveillance for HBV mutants (Review). Department of paediatrics and hepatitisResearch Centre, National Taiwan University Hospital, Taipel, Taiwan. 15: 463-469.

[19] National Programme on Immunization and Partners. (2002). Five Years National Strategic Plan 2003-2007. Abuja, Nigeria: National Programme on Immunization, 19-20.

[20] Nguyen, VT., Law, MG., Dore, GJ. (2011). Hepatitis B-related hepatocellular carcinoma: Epidemiological persistent risk for hepatocellular carcinoma: Prospect for an HBV cure. Diseases. 54:753-756.

[21] Okoye, FN., Anaku, AS., Ocheke, AN., Musa, J., Sagay AS. (2015). Burden and determinants of hepatitis B virus co-infection in a cohort of HIV positive pregnant women in Jos, Nigeria. Int J Trop Dis Health; 9:1-9.

[22] Olokoba, AB., Salawu, FK., Danburam, A., Desalu, OO., Olokoba, LB., Wahab, KW. (2009). Viral hepatitis in voluntary blood donors in Yola, Nigeria. Euro J Scientific Res 31: 329-334.

[23] Olumuyiwa, O., Odusanya, Ewan Alufohai, Francois, P. Meurice and Vincent, I. Ahonkhai, (2011). Five Year Post Vaccinaion Efficacy of Hepatitis B Vaccine in Rural Nigeria. Human Vaccines. 7:6, 625-629.

[24] Rendi-Wagner P., Korinek, M., Winkler, B., Kundi, M., Kollaritsch, H., Wiedermann, U. (2007). Persistence of seroprotection 10 years after Primary Hepatitis A Vaccination in an unselected Study Population. Vaccine; 25:927-31.

[25] Senior, JR., London, WT., Sutnick, AI. (2018). The Australia antigen and role of the late Philadelphia general hospital in reducing post-transfusion hepatitis and sequelae. Hepatology 6: .27-33.

[26] Spearman, CW., Afihene, M., Ally, R., Apica, B., Awuku, Y., Cunha, L. (2017). Hepatitis B in sub-Saharan Africa: strategies to achieve the 2030 elimination targets. Lancet Gastroenterol Hepatol; 2: $900 \quad 9$.

[27] Uneke, CJ. Ogbu, O., Inyama, PU, Anyawu, Njoku, M.O., \& Idoko, JH (2005). Prevalence of Hepatitis B Surface Antigen among Blood Donors, and Human Immunodeficiency Virus Infected Patients in Jos, Nigeria. Mem Inst Oswaldo Cruz, Rio de Janeiro, Vol. 100(1); $\quad 13-16$

[28] Villeneuve, JP. (2015). The natural history of chronic hepatitis B virus infection. Journal of Clinical Virology. 2005; 34 (Suppl 1):S139S142.

[29] Weinberger, B., Keller, M., Fischer, KH, Striasny K, Neuner C, Heinz FX, Grubeck-Loebenstein B,(2010). Antibody Titers and Booster Response in Tick-born Encephalitis Vaccinees Aged 50-90 Years. Vaccine; 28(20): 3511-5.

[30] Wiedermann, U., Garner-Spitzer, E, and Wagner, A, (2016).Primary Vaccine Failure to Routine Vaccines: Why and what to do? Human Vaccine \& Immunotherapeutic 12:1,239-243

[31] World Health Organization, (2016). WHO Global health sector strategy on viral hepatitis 2016- 2021: towards ending viral hepatitis. Geneva: WHO; 2016 Available apps.who.int/iris/bitstream/10665/246177/1/WHO-HIV-2016.06eng.pdf. (Last accessed 25February 2017.

[32] World Health Organization. Global hepatitis report Geneva. (2017) Available at: www.who.int/hepatitis/publications/globalhepatitisreport2017/en/. (Last accessed 13 May 2019. 
[33] Yan, H., Zhong, G., Xu, G., He, W., Jing, Z., Gao, Z., Huang, Y., Qi, Y., Peng, B., Wang, H., Fu, L., Song, M., Chen, P., Gao, W., Ren, B., Sun, Y. Cai, T., Feng, X., Sui, J., Li, W. (2012). Sodium taurocholate cotransporting polypeptide is a functional receptor for human hepatitis $\mathrm{B}$ and $\mathrm{D}$ virus. Elife, 1: 41-49.

[34] Yang, PL., Althage, A., Chung, J., Maier, H., Wieland, S., Isogawa, M, Chisari, FV. (2010). Immune effectors required for hepatitis B virus clearance. Proceedings of the National Academy of Sciences of the United States of America. 107:798-802.

\section{AUTHORS}

First Author - Kyauta Mallam Thomas: Department of

Microbiology, faculty of natural sciences University of Jos
Nigeria. Email: kyautathomas@ymail.com, Phone: $+2347036181047$

Second Author - Patricia Manko Lar: Department of Microbiology, Faculty of Natural Sciences, University of Jos, Nigeria

Third Author - Hashimu Zakari: Department of Microbiology, Faculty of Natural Sciences, University of Jos, Nigeria Fourth Author - Tabitha Vem Silas: Department of Medical Laboratory Sciences, Faculty of health Sciences University of Jos Nigeria 